\title{
Debris Run-Out Modeling Without Site-Specific Data
}

\author{
NMT De Silva ${ }^{1}$, Prasad Wimalaratne ${ }^{2}$ \\ University of Kelaniya, Sri-Lanka ${ }^{1}$ \\ University of Colombo School of Computing, Sri-Lanka ${ }^{2}$
}

\begin{abstract}
Recent population growth and actions near hilly areas increase the vulnerability of occurring landslides. The effects of climate change further increase the likelihood of landslide danger. Therefore, accurate analysis of unstable slope behavior is crucial to prevent loss of life and destruction to property. Predicting landslide flow path is essential in identifying the route of debris, and it is essential necessary component in hazard mapping. However, current methodologies of determining the flow direction of landslides require costly sitespecific data such as surface soil type, categories of underground soil layers, and other related field characteristics. This paper demonstrates an approach to predict the flow direction without site-specific data, taking a large landslide incident in Sri Lanka at Araranyaka region in the district of Kegalle as a case study. Spreading area assessment was based on deterministic eight-node (D8) and Multiple Direction Flow (MDF) flow directional algorithms. Results acquired by the model were compared with the real Aranayaka landslide data set and the landslide hazard map of the area. Debris paths generated from the proof of concept software tool using the D8 algorithm showed greater than $76 \%$ agreement, and MDF showed greater than $87 \%$ agreement with the actual flow paths and other related statistics such as maximum width of the slide, run-out distance, and slip surface area.
\end{abstract}

Keywords-Landslide flow path; route of debris; hazard mapping; D8 Algorithm; multiple direction flow algorithm

\section{INTRODUCTION}

A landslide is widespread in earth motion when the slope changes from a steady to an unsteady state. It happens due to geological, morphological causes, or human activities. There are many categories of landslides, namely Rock Slides, Earth Flows, Debris Slides, Debris Flows, and Rock Falls [1].

Rainfall is a major initiating factor for most landslides in Sri Lanka [2]. During heavy rains, water penetrates the top layer of soil into the deep layers of the earth beneath them, filling the ground's empty pores. When the water in the pores reaches saturation, it causes an internal pressure, called the "pore pressure of water," and in most cases, it causes a landslide.

Predicting a landslide flow path is very important for determining the flow path and the sedimentation area. It is also vital for mapping the hazards of landslides, early warnings, evacuation, and mitigation. Hence flow direction is a prime component in risk assessment and measures to eliminate rapid landslides [3].

When dispensing early warnings, it is impossible to visit every site before issuing of warning. Even without site-specific information, if there is a method that can be used to get an idea of the landslide-prone area, accordingly, the landslide's flow path can be predicted, and evacuation paths can be decided. Instructing people as per prediction will reduce the possible damages to lives during the landslide. Therefore, this work can be used to get an idea about the elevation and possible flow paths of a site prior to visiting without expensive site-specific data.

\section{LITERATURE REVIEW}

Many research works have been carried out globally to predict, mitigate, and manage these disasters and do better decision-making. The following are some attempts done by people worldwide to predict landslide initiation points, flow path, and run-out distance.

The paper by Gomes et al. [4] elaborates on how to combine spatial models for landslides and flows prediction. A map has been constructed with landslides starting points, flows size, and run-out distance of mass movements in Quitite and Papagaio in Rio de Janeiro city, Brazil, using this combined model. In this study, the landslide model (SHALSTAB) was combined with the debris-flow simulation model (FLO-2D).

In 2020, Zhao et al. came up with landslide run-out modeling method [5] with the integration of Gaussian process emulation and open-source simulation tool r.avaflow.The developed model is then tested with the landslide that happened in Bondo in 2017.

Tesfahunegn Abera Gebreslassie carried out dynamic simulations of landslide run-out for his master's research using DAN3D and BING models [6]. Finneidfjord quick-clay landslide has been taken as the case study to stimulate the above models. DAN3D and BING models require terrain models of the path and the mass at the release area, shear strength, and the dynamic viscosity as inputs and calculate the run-out distance and the flow velocity. This study shows that the run-out distance is higher using DAN3D than the BING model; however, DAN3D uses ten times execution time than the BING model.

"Linking rainfall-induced landslides with debris flows runout patterns towards catchment scale hazard assessment", a paper by LinfengFan et al. [7] described a methodology to predict landslide pathways with the integration of the novel Landslide Hydro-mechanical Triggering (LHT) model. The obtained result is compared with the continuum-based model RAMMS, which showed a reasonable agreement.

In 2016, a paper presented by Formetta et al. came up with a methodology to systemically calibrate, verify, and compare different models and select the models whose behavior is the most reliable for a particular case study. This approach 
integrates the hydrological model package (NewAge-JGrass) and other components, such as the uDig open-source geographic information system, physically based landslide susceptibility model, parameter calibration algorithm, and a model for pixel-by-pixel comparison of modeled and actual landslide [8]. The procedure was applied in a test case on the Salerno-Reggio Calabria highway landslide with adequate performance. This integrated method would be useful for landslide early warning systems and decision-makers dealing with risk management assessments.

Syah et al. have presented a paper describing a numerical analysis of landslide movements [9]. For this paper, erosion and deposition along the flow path have taken into consideration, and the model has tested with landslides, which were previously attempted by Egashira et al. [10], McDougall and Hungr [11], and Blanc [12]. The result achieved by this study showed more accurate predictions than previous attempts.

Landslide run-out analysis - current practice and challenges by Scott McDougall, presented a useful review of tools and methods that have been developed, challenges faced by researchers, challenges solved by researchers, simulation of debris flows, and potential future works [13].

The above literature related to landslide flow path modeling required expensive fieldwork at landslide incurred or landslideprone sites. The proposed methodology can be used to get an idea of the landslide flow path even without site-specific information. This work can also be used as a tool for geologists to get an idea about the elevation and possible flow paths and other related statistics of a site before visiting for investigations.

\section{DESIGN AND IMPLEMENTATION}

The development of the model is done using MATLAB $\mathrm{R} 2017$. MATLAB image processing toolbox is used for the analysis of Digital Elevation Models (DEMs). The developed tool followed an object-oriented programming (OOP) approach to build flow directions and stream networks. Fig. 1 shows the methodology carried out.

\section{A. Data Pre-Processing}

Contour data formatted as shape file was obtained from the Sri Lanka Survey Department. These files were converted to ASCII format, which is a convenient format to MATLAB. The conversion is done by using the inbuilt functions of ArcGIS software.

\section{B. Generate DEM using ASCII Data}

DEM is widely used in various hydrological modeling. It can be joint with other data sets, such as rainfall data and penetration capability for practical use.

A $10 \mathrm{~m}$ resolution couture data was used to obtain DEM of Aranayaka Landslide area. DEM file is created as a grid object which contains a numerical matrix and information on georeferencing. Grid object is associated with datasets such as flow accumulation grids, gradient grids. Created DEM has a projected coordinate system and that elevation and horizontal coordinates are in meter units.

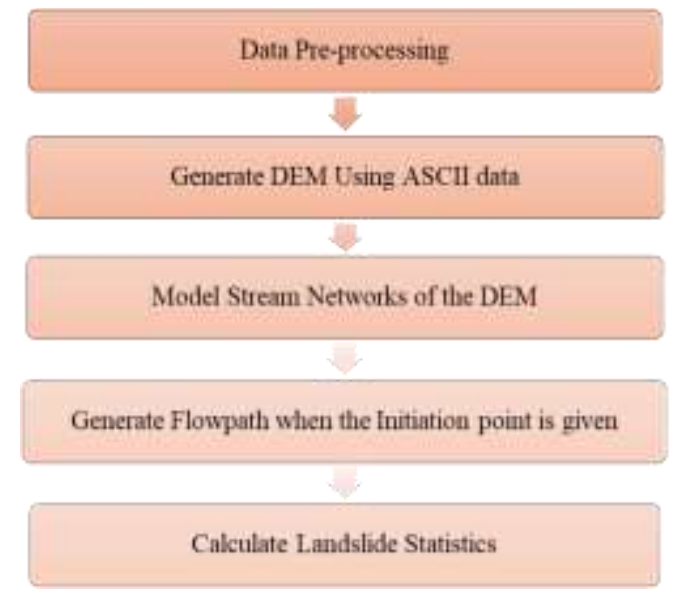

Fig. 1. Design Methodology.

The 2D-Euclidean distance between the two cells determines the physical location of each DEM cell. Euclidian distance (dij) defined as squared distances between two vectors, is the sum of squared differences in their coordinates $\left(\mathrm{x}_{\mathrm{i}}, \mathrm{x}_{\mathrm{j}}\right.$ and $\left.\mathrm{y}_{\mathrm{i}}, \mathrm{y}_{\mathrm{j}}\right)$, as shown in (1) [14].

$\mathrm{d}_{\mathrm{ij}}=\sqrt{ }\left(\llbracket\left(\mathrm{x}_{\mathrm{i}}-\mathrm{x}_{\mathrm{j}}\right)^{2}+\llbracket\left(\mathrm{y}_{\mathrm{i}}-\mathrm{y}_{\mathrm{j}}\right)^{2}\right)$

\section{Model Stream Networks of the DEM}

Based on a digital elevation model's flow direction, an instance of a stream object is created, which encapsulates the information on a stream network's geometry and connectivity.

\section{Generate Flow Path when the Initiation Point is given}

The debris flow run-out algorithms control the movement's direction from one cell to its eight neighboring cells. Single Directional Flow (SDF) and Multiple Directional Flow (MDF) algorithms were implemented, so the flow path's accuracy and other calculated statistics can be compared for better decisionmaking.

The D8 SDF algorithm is one of the primary and wellknown algorithms that lead flow from each cell to one of eight adjacent neighbors centered on the slope's incline. To calculate the primary flow, the slope $(\mathrm{Sij})$ direction to each neighboring cell has to be calculated and set the direction for the largest $\mathrm{Sij}$ [15].

$S_{i j}=\frac{Z_{i}-Z_{j}}{d_{i j}}$

The MDF algorithm divides and releases in each cell in several directions to all cells on a weighted slope basis. The slope gradients, slope lengths, and two weights are used to direct the center cell flow to each downslope cell in a $3 \times 3$ moving window. Every cell receives a portion of the release from each upslope cell, and hence, the upslope supporting area of the receiving cell is a collection of fractional contributions from many different cells [16]. In this study, both D8 and MDF algorithms are developed and tested. 


\section{E. Calculate Landslide Statistics}

Finally, the landslide statistics such as landslide area, runout distance, landslide crown, maximum width, and length of the main body were generated. The initiation points of the landslide are the primary user input to calculate the above statistics. These statistics were produced using flow paths generated from different flow routing algorithms.

Multiple points were selected from the D8, and MDF generated the landslide's main body for the calculations. As shown in Fig. 2 and Fig. 3, the initiation points and a point in the main body's toe were selected, and Euclidian distance between these points of the flow paths was calculated. From that, total main body area, crown width and maximum width is derived. All these statistics are calculated for both SDF and MDF flow paths.

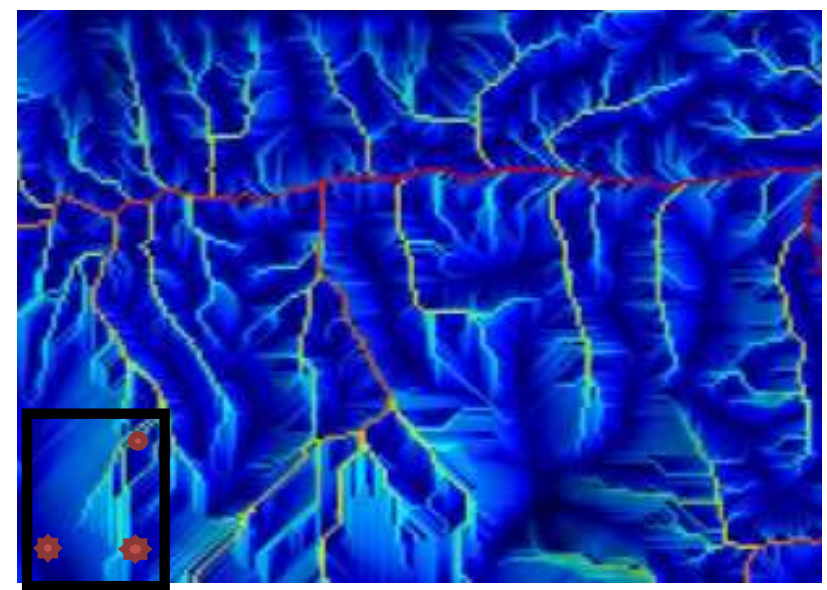

Fig. 2. Selected Points from the main Body of the Landslide (MDF).

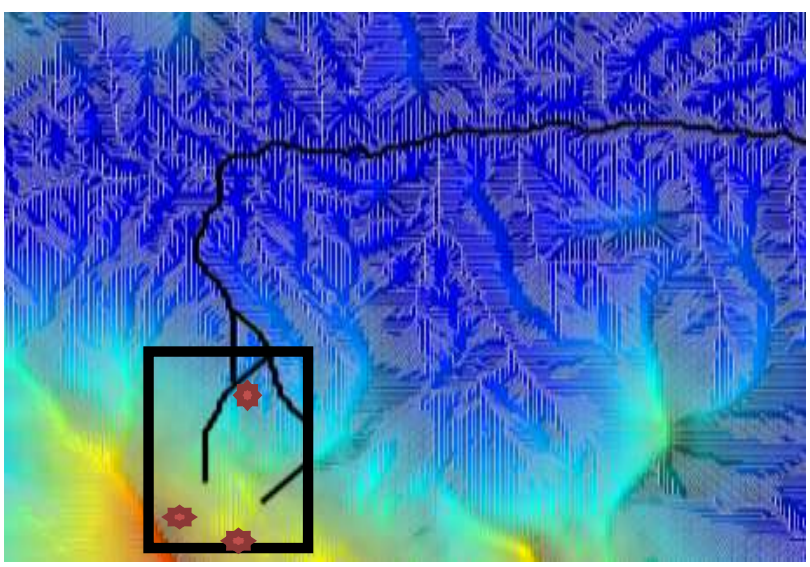

Fig. 3. Selected Points from the main Body of the Landslide (SDF).

\section{EVALUATION}

The developed model was evaluated using Aranayaka post landslide data such as drone images after the disaster, actual flow path, length of the landslide and flow volume. These statistics were taken as the baseline for the evaluation criteria and the accuracy of the generated statistics of this research was tested for compatibility and for deviations.

After creating all the available streams of the landslide area, the flow path is predicted with the given landslide initiation point. Afterward, the actual boundary created with ARCGIS was placed on top of the generated model to check for closeness. Fig. 4 shows the procedure carried out in the evaluation process.

\section{A. Identify the Actual Flow Path using Drone Images}

Unmanned Aerial Vehicles (UAV) is a technology used in worthwhile to capture images with Global Positioning System (GPS). Using drones for mapping is a fast, lost cost, safe and accurate method. The image processing methods can be used to pool the images and develop orthophoto from many different photos. Also, it helps to visualize the 3D image of the landslide.

DJI Panthom IV drone was used to collect material. "DGI Pro" and "Drone deploy" software were used to control the drone and Google Earth was taken as the base map. The flying path was manually set and continuous photos were taken during the mission. The drone captured multiple photos of each distinct feature, from multiple angles. Sufficient image overlap should be identified for better map detail and for efficient processing. In this case, $55 \%-65 \%$ image overlaps were preserved throughout the task. Altogether 577 images were taken to cover the entire landslide area.

Agisoft Photo scanner software was used to generate of 3D model and Digital Elevation Model (DEM). It is image processing software that automatically builds professional quality textured 3D models from a robust alignment of still images. Fig. 5 shows the generated DEM for Aranayaka landslide using drone images. The contours were produced from the generated DEM after the landslide, and contours prior to the landslide were obtained from secondary sources.

\section{B. Plot the Actual flow Path in the Location of the Landslide using GIS}

The goal is to verify the flow path of the Aranayaka Landslide generated by the model. For this purpose, the landslide flow path generated by drone images was plotted in the Aranayaka map by georeferencing Using ArcGIS. To map the landslide flow path, contour data of the studied area was taken from Sri Lanka Survey Department.

For evaluation of the carried-out work, Aranayaka landslide data were taken from the National Building Research Organisation (NBRO), which is designated as the leading national point for landslide managing in Sri Lanka. Using the data obtained from NBRO, the Aranayaka landslide area's actual boundary is generated on top of the contour map as shown in Fig. 6. The produced boundary is used to evaluate the model generated from MATLAB.

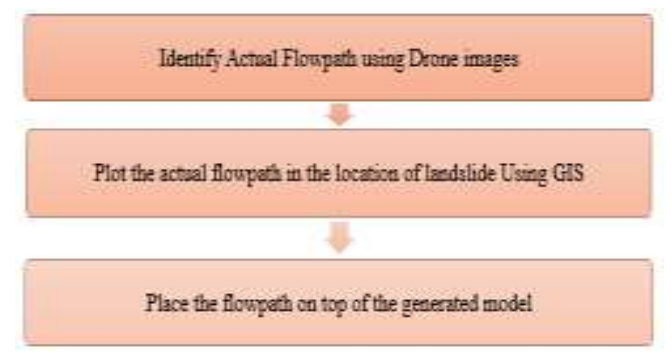

Fig. 4. Evaluation Methodology. 


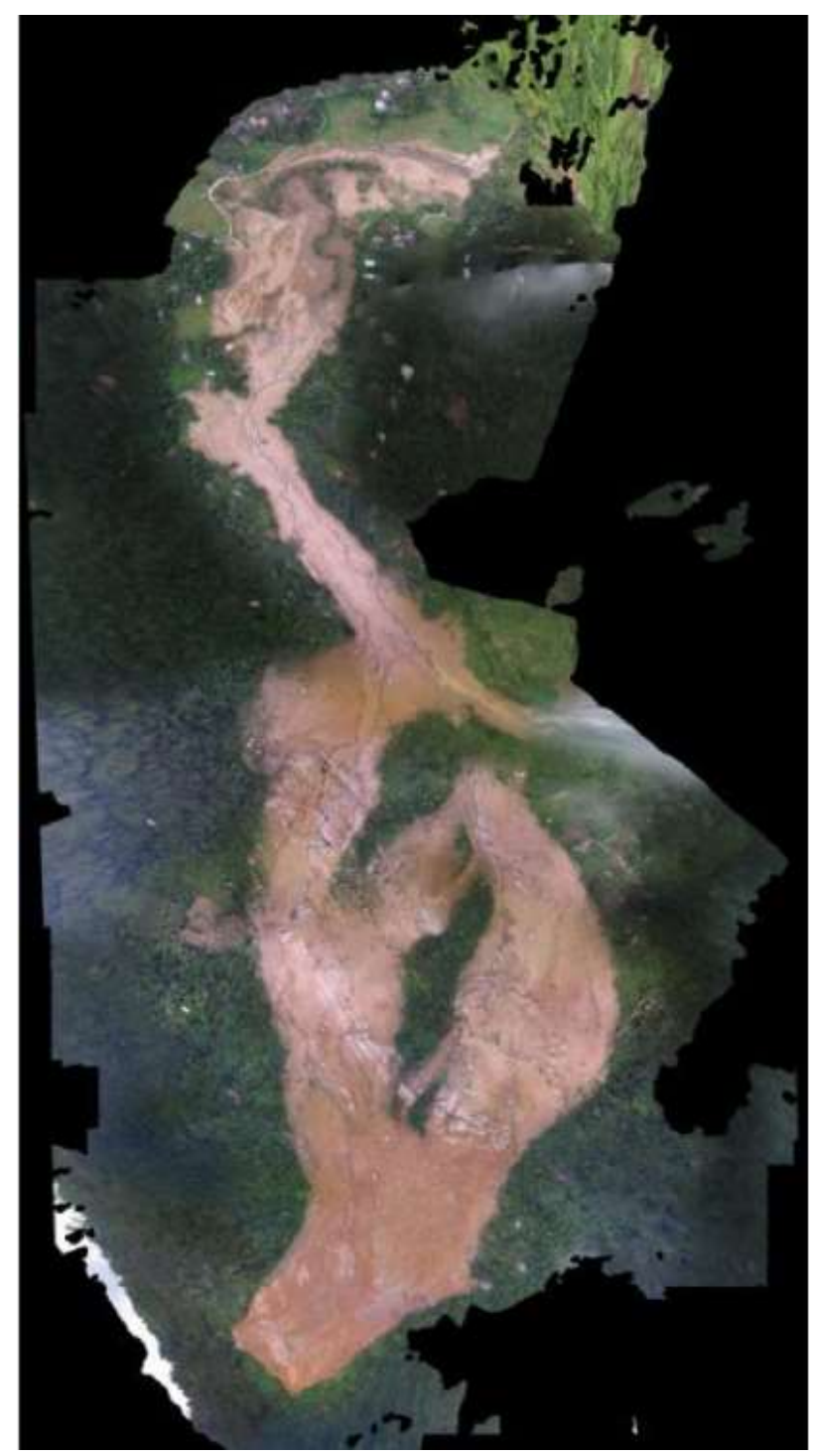

Fig. 5. DEM Created using Drone Images.

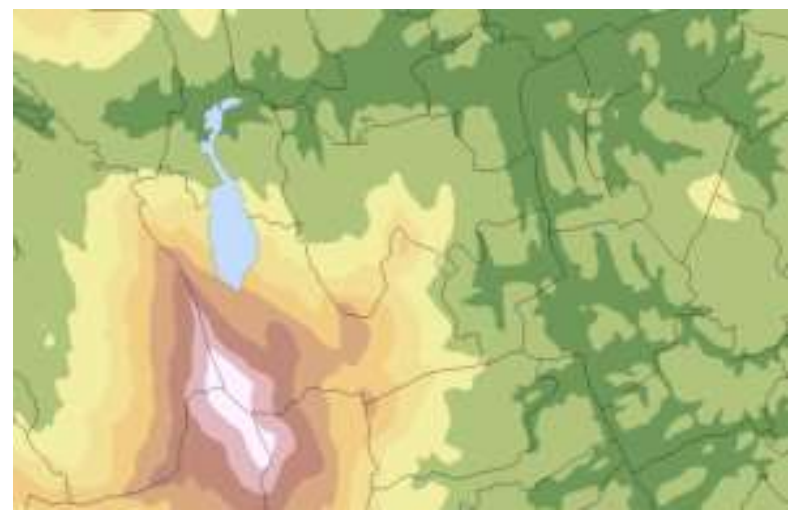

Fig. 6. Actual Landslide Flow Path Mapped in DEM.

\section{Place the Flow Path on Top of the Generated Model}

The actual landslide flow path mapped from ARCGIS in the previous step was placed on top of the model generated SDF and MDF flow paths by georeferencing as shown in Fig. 7 and Fig. 8.

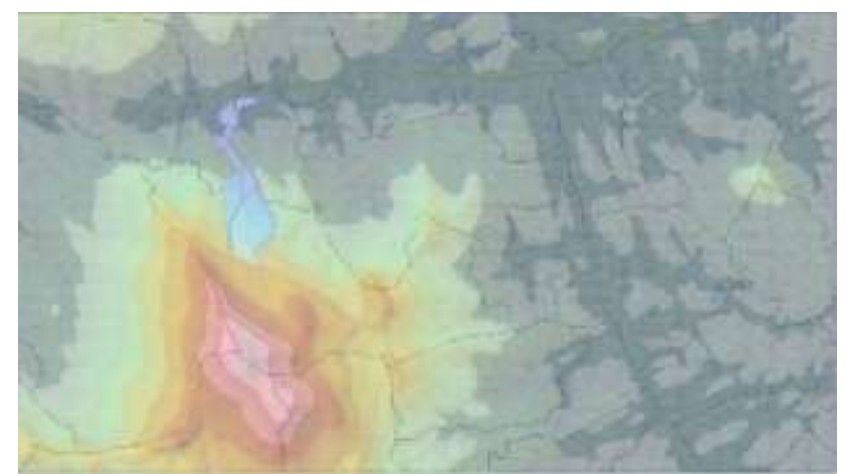

Fig. 7. Actual Landslide Flow Path Placed on the flow Path Generated from SDF.

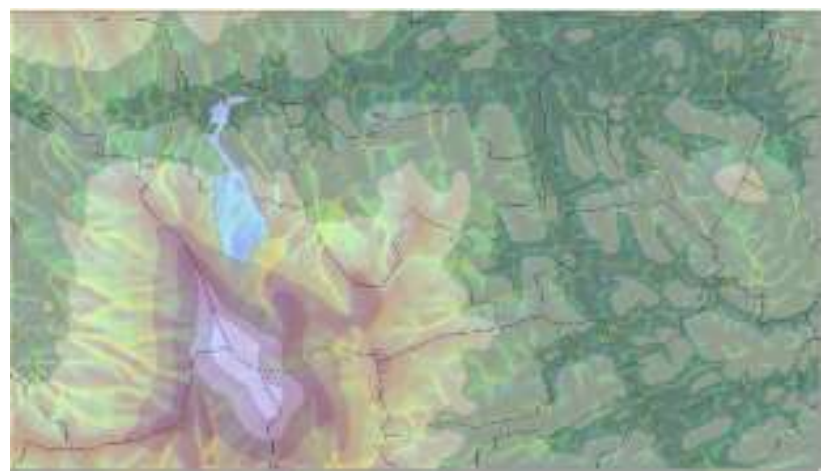

Fig. 8. Actual Landslide Flow Path Placed on the flow Path Generated from MDF.

\section{RESULTS}

Based on the result of different simulations, it is observed that both SDF and MDF flow paths fit inside the actual landslide boundary when the initiation points are given, and flow directions are also in the proper direction of the actual landslide.

Real landslide statistics were obtained from NBRO as per their detailed analysis and investigation carried at the actual landslide site area. These actual statistics and statistics generated from SDF and MDF are shown in the Table I.

Among the generated statistics, maximum width, length of the main body and flow length are critical indicators to identify the spreading area. So, people of the predicted perimeter can be alarmed to evacuate because the area is identified as high risk and landslide-prone. Also, safe evacuation paths can be determined by examining the predicted flow path of the landslide. Hence the lives of people will not be damaged during the evacuation process.

Table II shows the comparison SDF and MDF results deviation from actual landslide statistics. MDF algorithm produced the length of the main body of Aranayaka landslide as $1.29 \mathrm{Km}$, which is very close to the length of the main body of $1.26 \mathrm{Km}$. Also, MDF calculated the maximum width of the landslide deviates only $2.3 \%$ from the actual Aranayaka data. Both D8 and MDF algorithms generate a flow length of 1.925 $\mathrm{Km}$, which has a $15.1 \%$ of deviation from the actual flow length. As per the results, a more accurate flow path and statistics can be generated using MDF compared to SDF. 
TABLE I. COMPARISON OF RESULTS

\begin{tabular}{|l|l|l|l|}
\hline & Actual & SDF & MDF \\
\hline Area of Main Landslide Body & $0.56 \mathrm{Km}^{2}$ & $0.429 \mathrm{Km}^{2}$ & $0.488 \mathrm{Km}^{2}$ \\
\hline Landslide crown & $345.45 \mathrm{~m}$ & $329.8 \mathrm{~m}$ & $325.57 \mathrm{~m}$ \\
\hline Maximum Width & $600.07 \mathrm{~m}$ & $535.3 \mathrm{~m}$ & $619.9 \mathrm{~m}$ \\
\hline Length of the main body & $1.26 \mathrm{Km}$ & $1.02 \mathrm{Km}$ & $1.29 \mathrm{Km}$ \\
\hline Flow length & $2.268 \mathrm{Km}$ & $1.925 \mathrm{Km}$ & $1.925 \mathrm{Km}$ \\
\hline
\end{tabular}

TABLE II. Percentage of DeVIATION From the ACtUAL Statistic

\begin{tabular}{|l|l|l|}
\hline & SDF Deviation (\%) & MDF Deviation (\%) \\
\hline Main Landslide Body & 23.3 & 12.75 \\
\hline Landslide crown & 4.5 & 5.7 \\
\hline Maximum Width & 10.7 & 3.3 \\
\hline Length of the main body & 25.8 & 2.3 \\
\hline Flow length & 15.1 & 15.1 \\
\hline
\end{tabular}

\section{CONCLUSION AND FUTURE WORK}

The landslide flow paths and statistics predicted by the Proof of concept prototype shows good agreement with the actual landslide data collected for the selected case study. However, the MDF algorithm produced more fitting flow paths and relevant statistics for the selected landslide.

Deviation of the generated flow paths and other statistics would have caused due to the unavailability of site-specific data such as soil condition, soil type, spreading velocity, the volume of the slip surface, gravity, and other forces.

Even without knowing any of the site-specific data, this tool can be used and predict results with more than $87 \%$ accuracy with the landslide-prone area's couture data as the only input. When compare the implemented tool with the other flow path based tools such as FLOW-R, RAMMS, and DAN3D, all of these tools require site-specific data, which may difficult to collect from all landslide-prone sites prior to a landslide.

This study has been mainly based on Aranayaka Landslide area. This model can be expanded to fit with most of the Sri Lankan landslide context with additional work. Then it will give immense help to reduce the impact of a landslide as the flow path can be determined prior and evacuation paths can be decided accordingly before the disastrous situations. Also, other than used SDF and MDF algorithms, there are many more flow routing algorithms available. These algorithms also can be implemented and integrated with this model to compare the results for higher accuracy.
When calculating the run-out distance and spreading of the landslide, geotechnical information about the landslide is essential. Therefore, the implemented tool can be extended by integrating site-specific geology-related knowledge, checking for results produced with site-specific data and without sitespecific data, and testing for accuracy of predictions.

\section{REFERENCES}

[1] US Department of the Interior, "Landslide Types and Processes," July 2004. [Online]. Available: https://pubs.usgs.gov/fs/2004/3072/fs-20043072.html. [Accessed 20th September 2020].

[2] Nawagamuwa U.P., Perera L.P. (2017) Recommending Rainfall Thresholds for Landslides in Sri Lanka, Advancing Culture of Living with Landslides. WLF 2017.

[3] Eranga Dulanjalee ,Landslide Flow Path Assessment for Susceptibility Mapping at a Regional Scale, 8th Annual NBRO Symposium,January 2018.

[4] Roberto Arnaldo Trancoso Gomes, Renato Fontes, Osmar Abílio de Carvalho Júnior, Nelson Ferreira and Eurípedes Vargas do Amaral, "Combining Spatial Models for Shallow Landslides and Debris-Flows Prediction," Remote Sensing, no. 5, pp. 2219-2237, 2013.

[5] Zhao, H., Amann, F. and Kowalski, J., 2020. Emulator-based global sensitivity analysis for flow-like landslide run-out models. arXiv preprint arXiv:2010.04056.

[6] T. A. Gebreslassie, "Dynamic simulations of landslide run-out in cohesive Soils," Oslo, 2015.

[7] Fan, L., Lehmann, P., McArdell, B. and Or, D., 2017. Linking rainfallinduced landslides with debris flows runout patterns towards catchment scale hazard assessment. Geomorphology, 280, pp.1-15.

[8] Giuseppe Formetta, Giovanna Capparelli, and Pasqua, "Evaluating performance of simplified physically-based models for shallow landslide susceptibility," Hydrol. Earth System, no. 20, p. 4585-4603, 2016.

[9] Syah, A., Fathani, T.F. and Faris, F., 2019. A Numerical Analysis of Landslide Movements Considering the Erosion and Deposition along the Flow Path. In Journal of the Civil Engineering Forum (Vol. 5, No. 3, p. 187).

[10] Egashira, S., Itoh, T. and Takeuchi, H. (2001) 'Transition mechanism of debris flows over rigid bed to over erodible bed', Physics and Chemistry of the Earth, Part B: Hydrology, Oceans and Atmosphere. Elsevier, 26(2), pp. 169-174.

[11] McDougall, S. and Hungr, O. (2005) 'Dynamic modelling of entrainment in rapid landslides', Canadian Geotechnical Journal. NRC Research Press, 42(5), pp. 1437-1448.

[12] Blanc, T. (2008) Numerical simulation of debris flows with the 2D-SPH depth integrated model. na.

[13] S. McDougall, "Landslide run-out analysis - current practice and challenges," Canadian Geotechnical Colloquium, vol. 57, pp. 605-620, 2017.

[14] P.Barrett, Paul Barrett, Wikimedia Foundation, Inc, [Online]. Available: http://www.pbarrett.net/techpapers/euclid.pdf. [Accessed 1st July 2020].

[15] M. Cooper, "Depth Recovery through Linear Algibra," in Line Drawing Interpretation, Springer Science \& Business Media., p. 118.

[16] P. Quinn, K. Beven, P. Chevallier And O. Planchon, "The Prediction Of Hillslope Flow Paths For Distributed Hydrological Modelling Using Digital Terrain Models," Hydrological Processes, Vol. Vol. 5, Pp. 59-79, 1991. 